\title{
HbA1c and Aortic Calcification Index as Noninvasive Predictors of Pre-Existing Histopathological Damages in Living Donor Kidney Transplantation
}

\author{
Kosuke Tanaka ${ }^{1}$, Shigeyoshi Yamanaga ${ }^{1, *}$, Yuji Hidaka ${ }^{1}$, Sho Nishida ${ }^{1}$, Kohei Kinoshita ${ }^{1}$, \\ Akari Kaba ${ }^{1}$, Toshinori Ishizuka ${ }^{2}$, Satoshi Hamanoue ${ }^{2}$, Kenji Okumura ${ }^{1}{ }^{10}$, Chiaki Kawabata ${ }^{2}$, \\ Mariko Toyoda ${ }^{2}$, Asami Takeda ${ }^{3}$, Akira Miyata ${ }^{2}$, Masayuki Kashima ${ }^{2}$ and Hiroshi Yokomizo ${ }^{1}$ \\ 1 Department of Surgery, Japanese Red Cross Kumamoto Hospital, Kumamoto 861-8520, Japan; \\ kosuket0814@gmail.com (K.T.); yuji.h65@gmail.com (Y.H.); s.nishida06@gmail.com (S.N.); \\ kouhei7687@gmail.com (K.K.); momiji.akanashi@gmail.com (A.K.); kenjiokumura@kyudai.jp (K.O.); \\ h-yokomizo@kumamoto-med.jrc.or.jp (H.Y.) \\ 2 Department of Nephrology, Japanese Red Cross Kumamoto Hospital, Kumamoto 861-8520, Japan; \\ m03002ti@jichi.ac.jp (T.I.); ririgugu@yahoo.co.jp (S.H.); chiaki-kawabata@hotmail.co.jp (C.K.); \\ tmariko0413@gmail.com (M.T.); drmiyata19561@yahoo.co.jp (A.M.); \\ m-kashima@kumamoto-med.jrc.or.jp (M.K.) \\ 3 Department of Nephrology, Japanese Red Cross Nagoya Daini Hospital, Aichi 466-8650, Japan; \\ asamit@nagoya2.jrc.or.jp \\ * Correspondence: yamanaga@kumamoto-med.jrc.or.jp
}

Received: 1 September 2020; Accepted: 9 October 2020; Published: 12 October 2020

\begin{abstract}
We previously reported that allografts from living donors may have pre-existing histopathological damages, defined as the combination of interstitial fibrosis (ci), tubular atrophy (ct), and arteriolar hyalinosis (ah) scores of $\geqq 1$, according to the Banff classification. We examined preoperative characteristics to identify whether the degree of these damages was related to metabolic syndrome-related factors of donors. We conducted a single-center cross-sectional analysis including 183 living kidney donors. Donors were divided into two groups: chronic change (ci $+\mathrm{ct} \geqq 1 \cap \mathrm{ah} \geqq 1, n=27)$ and control $(n=156)$. Preoperative characteristics, including age, sex, blood pressure, hemoglobin A1c (HbA1c), aortic calcification index (ACI), and psoas muscle index (PMI), were analyzed. Comparing the groups, the baseline estimated glomerular filtration rate was not significantly different; however, we observed a significant difference for $\mathrm{ACI}(p=0.009)$. $\mathrm{HbA} 1 \mathrm{c}(p=0.016)$ and ACI $(p=0.006)$ were independent risk factors to predict pre-existing histopathological damages, whereas PMI was not. HbA1c correlated with ct scores $(p=0.035)$, and ACI correlated with ci $(p=0.005)$, ct $(p=0.021)$, and ah $(p=0.017)$. HbA1c and ACI may serve as preoperative markers for identifying pre-existing damages on the kidneys of living donors.
\end{abstract}

Keywords: renal aging; renal function recovery; $\mathrm{HbA1c}$; aortic calcification index

\section{Introduction}

Renal transplantation is the best option for patients with end-stage renal disease (ESRD) [1]. In Japan, the scarcity of deceased donors demands the need for new marginal living donors [1]. As the long-term ESRD risk for living donors is higher than that for the general health population [2,3], marginal living donors should be carefully selected [4-6].

We have recently reported that healthy living donors may have pre-existing histopathological damages at baseline biopsy ( $1 \mathrm{~h}$ after the reperfusion) [7]. This finding of chronic change (CC), defined by the combination of interstitial fibrosis (ci), tubular atrophy (ct), and arteriolar hyalinosis 
(ah) scores according to the Banff classification [8] (ci $+\mathrm{ct} \geqq 1 \cap$ ah $\geqq 1$ ), is strongly associated with suboptimal recovery of the renal function in living donors 1 year after donation [7]. This combination represents the extent of renal chronic deterioration. Positive ci and ct scores correspond to the interstitial fibrosis/tubular atrophy (IF/TA), which is a final pathway and prognostic factor of chronic kidney damages $[9,10]$. A positive ah score corresponds to the chronic afferent arteriolar change observed in metabolic syndromes, including hypertension and diabetes [11,12]. Furthermore, the impact of the chronicity score was independent of the actual age [7].

This age-histology discrepancy implicated the fact that even eligible, healthy living donors with subclinical metabolic syndrome could have pre-existing histopathological damages. Many clinical studies suggested that metabolic syndromes such as hypertension [13-15], hyperglycemia [16,17], and dyslipidemia $[18,19]$ were correlated with the deterioration of renal function in the general population, and subclinical signs of aging, a consequence of metabolic syndrome, such as aortic calcification and sarcopenia were common in patients with chronic kidney disease (CKD) [20,21]. However, the relationship between these subtle signs of metabolic syndromes and pre-existing histopathological damages in the healthy living donors is unclear.

Metabolic syndromes are also associated with glomerular hyperfiltration [22]. Increased glomerular pressure and hypertrophy by altered hemodynamics induces glomerular hyperfiltration and finally results in renal deterioration [23]. Remnant kidneys are also injured by donation-induced glomerular hyperfiltration after living donation [24]. Therefore, the subtle signs of metabolic syndromes are more critical in living donors.

Furthermore, noninvasive clinical markers would be preferred to invasive biopsies for living donors, because we could then preoperatively forecast histopathological damages and factor them into the living donor selection process.

Thus, we aimed to identify the predictive metabolic syndrome-related factors that would forecast pre-existing histopathological damages on the kidneys of living donors.

\section{Materials and Methods}

\subsection{Study Population}

This was a single-center cross-sectional study. Between May 2011 and Jan 2020, a total of 187 living kidney transplantations were performed at the Japanese Red Cross Kumamoto Hospital. Four cases were excluded due to unavailability of data on baseline biopsies. The 183 remaining cases were divided into two groups, according to our previous report [7] as previously noted: CC group (ci $+\mathrm{ct} \geqq 1 \cap \mathrm{ah} \geqq 1, n=27)$ and control group $(n=156)$. We analyzed preoperative characteristics as possible predictive factors, including age, sex, tobacco use, blood pressure, hypertension, $\mathrm{HbA1c}$ concentration, uric acid concentration, low-density lipoprotein (LDL) concentration, ACI, body mass index (BMI), 3rd lumber PMI, and preoperative estimated glomerular filtration rate (eGFR). HbA1c, ACI, LDL, and PMI were examined as clinical indicators of hyperglycemia, aortic calcification, dyslipidemia, and sarcopenia, respectively. The detailed definitions and measuring methods of ACI and PMI are described in the subsequent chapters in this manuscript.

All donors were selected by strictly complying to the Japanese donor selection criteria [25]. This study was approved by the Institutional Review Board of Japanese Red Cross Kumamoto Hospital (study approval number 411). The review board waived the requirements of informed consent according to the nature of this research. None of the transplant donors were from a vulnerable population, and all donors or their next of kin provided freely given written informed consent.

\subsection{Pathological Diagnosis}

Baseline kidney biopsy was defined as a biopsy performed at 1 hour after reperfusion during the kidney transplantation [26]. Baseline biopsy data were collected retrospectively from the pathological reports. No other biopsies with different timings or causes (e.g., one-year protocol biopsy or 
episode biopsy) were included in this study. A Banff classification was used to assess pre-existing histopathological damages [8]. This classification enabled us to generalize and compare the degree of renal damages for the further analysis on living donor renal transplant recipients.

According to the Banff classification [8], histopathological findings were classified as ci, ct, and ah; ci referred to interstitial fibrosis, ct to tubular atrophy, and ah to arteriolar hyalinosis. Based on the cortical area percentage, the ci was classified as minimal ( $\leqq 5 \%)$, mild $(6-25 \%)$, moderate $(26-50 \%)$, or severe ( $\geqq 50 \%)$, which corresponded to ci-0, ci-1, ci-2, and ci-3, respectively. Ct was similarly categorized as ct- 0 , ct- 1 , ct- 2 , and ct- 3 . Ah was classified as none, mild-to-moderate, moderate-to-severe, or severe, corresponding to Banff scores of ah- 0 , ah- -1 , ah-2, and ah-3, respectively. As previously reported [7], we defined pre-existing histopathological damages as the combination of ci, ct and ah scores $(\mathrm{ci}+\mathrm{ct} \geqq 1 \cap \mathrm{ah} \geqq 1)$.

\subsection{Recording and Assessment of Clinical Data}

We retrospectively collected all clinical data from medical records. The blood pressure in most donor cases was determined from 24-h blood pressure monitoring, and the average values of the systolic blood pressure obtained in the afternoon were adopted. We defined hypertensive donors as those who had an average systolic blood pressure of $\geqq 140 \mathrm{mmHg}$, or those who took $\geqq 1$ antihypertensive drugs. $\mathrm{HbA1c}$ data were collected from the initial drawing samples (mainly three months before donor nephrectomy). In 21 cases, $\mathrm{HbA1c}$ measured using the Japan Diabetes Society (JDS) methods were converted into the National Glycohemoglobin Standardization Program (NGSP) $\mathrm{HbA1c}$ value according to the following formula [27]: NGSP value $(\%)=1.02 \times$ JDS value $(\%)+0.25 \%$. $\mathrm{HbA1c}$ was also described in accordance with the International Federation of Clinical Chemistry and Laboratory Medicine (IFCC) and reported as $\mathrm{mmol} / \mathrm{ml}$ according to the following formula [28]: IFCC value $(\mathrm{mmol} / \mathrm{mol})=10.93 \times \mathrm{NGSP}$ value $(\%)-23.50 \mathrm{mmol} / \mathrm{l}$. eGFR was calculated by the formula recommended by the Japanese society of nephrology as [29]: $\operatorname{eGFR}\left(\mathrm{ml} / \mathrm{min} / 1.73 \mathrm{~m}^{2}\right)=194 \times \mathrm{Cr}^{1.094} \times \mathrm{Age}^{0.28}$ in male donors and $194 \times \mathrm{Cr}^{1.094} \times \mathrm{Age}^{0.28} \times 0.739$ in female donors.

\subsection{Aortic Calcification Index}

ACI was examined as a clinical indicator of aortic calcification. ACI represents the calcification proportion of the abdominal aorta [30] and is calculated as the sum of the aortic calcifications evaluated from multidetector computed tomography (CT) images, with a window level of 30 Hounsfield unit (HU) and window width of $260 \mathrm{HU}$. We did not set the cutoff levels for the ACI analysis because the contrast between calcification and a healthy aortic wall was obvious enough not to rely on an arbitrary HU cutoff. ACI (\%) was calculated by the following formula: $\mathrm{ACI}=$ (total score for calcification on all 10 slices)/120 $\times 100(\%)$. The score of calcifications was manually assessed by dividing the aorta into 12 sectors on each slice. Ten slices above the bifurcation of the aorta were added at every $10 \mathrm{~mm}$ interval. The ACI of the diabetic hemodialysis patients has been reported to be $57.3 \pm 22.1 \%$, and the ACI of predialysis chronic kidney disease patients has been reported to range from $0 \%$ to $76.6 \%$, with a median of $11.4 \%$ [30,31].

\subsection{Third Lumber Psoas Muscle Index}

PMI is one of the methods used to evaluate the degree of sarcopenia [32]. The total areas of the right and left psoas muscles at the L3 level were measured by a manual tracing method using preoperative CT imaging. PMI was calculated as the division of the total psoas muscle area by muscle area square height $\left(\mathrm{cm}^{2} / \mathrm{m}^{2}\right)$. According to the prior study for living liver donors, the normal value of PMI was $8.85 \pm 1.61 \mathrm{~cm}^{2} / \mathrm{m}^{2}$ (mean, standard deviation) in men and $5.77 \pm 1.21 \mathrm{~cm}^{2} / \mathrm{m}^{2}$ in women [32]. 


\subsection{Statistical Analysis}

All data were analyzed using IBM ${ }^{\circledR}$ SPSS ${ }^{\circledR}$ Statistics, version 25 (IBM Corp., Chicago, IL, USA). Data were expressed as the median and interquartile ranges for continuous data. In addition, for continuous data, a student's $t$ test, Mann-Whitney test and Kruskal Wallis tests were also used depending on the distribution of the data. The Chi-squared $\left(\chi^{2}\right)$ test was used for categorical data. Preoperative factors were analyzed with the univariable and multivariable logistic regression analyses after controlling them simultaneously for potential confounders. The interaction analysis was used to identify the relationship between male and female donors. The variables included age, sex, tobacco use, blood pressure, hypertension, $\mathrm{HbA1c}$, uric acid, LDL, ACI, BMI, PMI, and eGFR. The multivariable analysis was performed using four potential predictors: tobacco use, $\mathrm{HbA} 1 \mathrm{c}$, uric acid, and ACI, because their $p$-values were less than 0.1 . The optimal cutoff points of preoperative continuous data in the prediction of chronic kidney damages were determined using a ROC curve analysis, and the AUC was calculated to assess the accuracy. A $p$-value $<0.05$ was considered statistically significant. The authors have followed the suggestions of the Strengthening the Reporting of Observational Studies in Epidemiology statement guidelines for reporting observational studies [33].

\section{Results}

\subsection{Donor Characteristics}

The donor characteristics are shown in Table 1 . The median age of all donors was 58 years. Sixty-five donors $(35.3 \%)$ were male. Twenty donors $(10.9 \%)$ were older than 70 years of age. Donors with a history of tobacco use and hypertension were $27.2 \%$ and $32.1 \%$, respectively. The psoas muscle index (PMI) was $5.88(5.05-7.21) \mathrm{cm}^{2} / \mathrm{m}^{2}$ in male donors and $3.90(3.41-4.42) \mathrm{cm}^{2} / \mathrm{m}^{2}$ in female donors.

Table 1. Baseline characteristics.

\begin{tabular}{|c|c|c|c|c|}
\hline & All Donors $(n=183$ ) & Chronic Change (CC) $(n=27)$ & Control $(n=156)$ & $p$ Value \\
\hline Sex: male $(\%)$ & $65(35.3)$ & $13(48.1)$ & $52(33.3)$ & 0.138 \\
\hline Age (years) & $58(51.0-65.0)$ & $60(52.0-69.0)$ & $58(50.0-65.0)$ & 0.174 \\
\hline Tobacco use, $n(\%)$ & & & & 0.035 \\
\hline Nonsmoker & $102(55.4)$ & $10(37.0)$ & $92(59.0)$ & \\
\hline Current smoker & $32(17.4)$ & $9(33.3)$ & $23(14.7)$ & \\
\hline Ex-smoker & $18(9.8)$ & $3(11.1)$ & $14(9.0)$ & \\
\hline $\mathrm{BP}(\mathrm{mmHg})$ & $124(115.0-136.0)$ & $124(118.0-133.0)$ & $123(114.3-136.8)$ & 0.381 \\
\hline Hypertension, $n(\%)$ & $59(32.1)$ & $11(40.7)$ & $48(30.8)$ & 0.306 \\
\hline HbA1c (\%) & $5.6(5.4-5.9)$ & $5.7(5.5-6.1)$ & $5.6(5.4-5.8)$ & 0.057 \\
\hline$(\mathrm{mmol} / \mathrm{mol})$ & $38.0(36.0-41.0)$ & $39.0(37.0-43.0)$ & $38.0(36.0-40.0)$ & \\
\hline Uric acid (mg/dl) & $4.9(4.2-5.7)$ & $5.4(4.6-6.3)$ & $4.8(4.1-5.6)$ & 0.029 \\
\hline LDL (mg/dl) & $120(102.0-138.0)$ & 123. $(101.0-137.0)$ & $118(103.3-138.8)$ & 0.766 \\
\hline $\mathrm{ACI}(\%)$ & $0.83(0.0-5.0)$ & $3.33(0.0-13.3)$ & $0.83(0.0-4.2)$ & 0.009 \\
\hline BMI $\left(\mathrm{kg} / \mathrm{m}^{2}\right)$ & $22.9(20.9-25.1)$ & $22.7(21.5-25.4)$ & $22.9(20.8-24.9)$ & 0.473 \\
\hline PMI $\left(\mathrm{cm}^{2} / \mathrm{m}^{2}\right)$ & $4.40(3.69-5.57)$ & $4.68(3.72-5.68)$ & $4.36(3.69-5.56)$ & 0.511 \\
\hline eGFR $\left(\mathrm{ml} / \mathrm{min} / 1.73 \mathrm{~m}^{2}\right)$ & $81.1(73.0-91.8)$ & $86.2(74.0-94.7)$ & $81.1(73.0-91.6)$ & 0.386 \\
\hline ci, $n(\%)$ & & & & $<0.001$ \\
\hline 0 & $160(87.4)$ & $18(66.7)$ & $142(91.0)$ & \\
\hline 1 & $20(10.9)$ & $6(22.2)$ & $14(9.0)$ & \\
\hline 2 & $3(1.6)$ & $3(11.1)$ & $0(0)$ & \\
\hline 3 & $0(0)$ & $0(0)$ & $0(0)$ & \\
\hline ct, $n(\%)$ & & & & $<0.001$ \\
\hline 0 & $114(62.3)$ & $1(3.7)$ & $113(72.4)$ & \\
\hline 1 & $66(36.1)$ & $23(85.2)$ & $43(27.6)$ & \\
\hline 2 & $3(1.6)$ & $3(11.1)$ & $0(0)$ & \\
\hline 3 & $0(0)$ & $0(0)$ & $0(0)$ & \\
\hline $\mathrm{ci}+\mathrm{ct} \geq 1, n(\%)$ & $71(38.8)$ & $27(100)$ & $44(28.2)$ & $<0.001$ \\
\hline ah, $n(\%)$ & & & & $<0.001$ \\
\hline 0 & $123(67.2)$ & $0(0)$ & $123(78.8)$ & \\
\hline 1 & 30 (16.4) & $13(48.1)$ & 17 (10.9) & \\
\hline 2 & $26(14.2)$ & $13(48.1)$ & $13(8.3)$ & \\
\hline 3 & $4(2.2)$ & $1(3.7)$ & $3(1.9)$ & \\
\hline
\end{tabular}

Median (IQR). BP: blood pressure. HbA1c: hemoglobin A1c. LDL: low-density lipoprotein. ACI: abdominal calcification index. BMI: body mass index. PMI: 3rd lumber psoas muscle index. eGFR: estimated glomerular filtration. ci: interstitial fibrosis. ct: tubular atrophy. ah: arteriolar hyalinosis. 
There was a significant difference between the chronic change (CC) group and control group regarding tobacco use $(p=0.035)$, uric acid (CC vs. control: $5.4 \mathrm{mg} / \mathrm{dL}(4.6-6.3)$ vs. $4.8 \mathrm{mg} / \mathrm{dL}(4.1-5.6)$, $p=0.029)$, and ACI (CC vs. control: $3.33(0.0-13.3)$ vs. $0.83(0.0-4.2), p=0.009)$. The age and preoperative estimated glomerular filtration rate (eGFR) did not differ between groups. In the CC group, 18 cases $(66.7 \%)$ had minimal ci (ci-0), whereas there was only one case $(3.7 \%)$ with minimal ct (ct-0). No cases had minimal ah (ah0). All CC group donors had identical ci and $c t(c i+c t \geqq 1)$. Living donors who were older than 70 years showed a tendency for positive pathological scores: ci1-3 (25\%), ct1-3(50\%), and ah1-3 (45\%).

The frequency of $\mathrm{ACI}$ is demonstrated in Figure 1 . The ACI was not normally distributed and $0 \%$ in 84 cases $(45.9 \%)$. Eight donors $(29.6 \%)$ in the CC group and 76 donors $(48.7 \%)$ in the control group had an ACI of $0 \%$. Eighteen donors (66.7\%) in the CC group and 137 donors (87.8\%) in the control group had an ACI of less than $10 \%$.

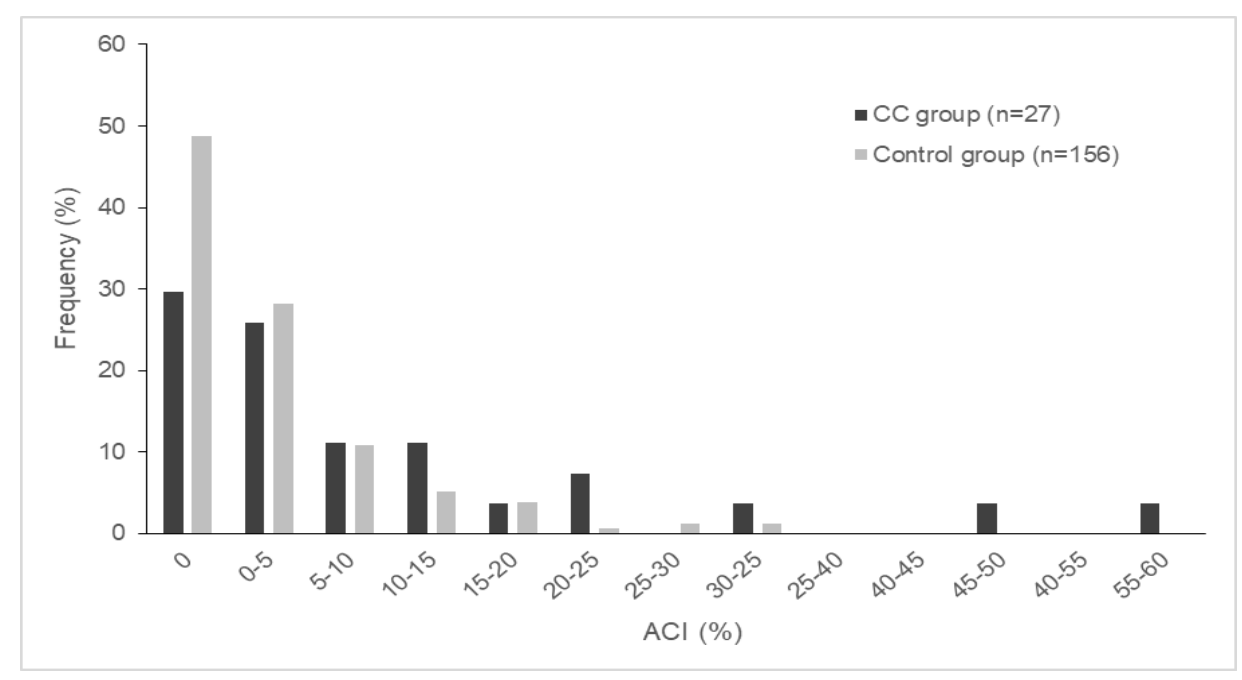

Figure 1. The distribution of ACI. ACI: abdominal calcification index. CC: chronic change.

\subsection{Preoperative Predictors}

Table 2 shows the results of the logistic regression analysis. The univariable analysis demonstrated that there was a significant difference in hemoglobin A1c (HbA1c) (odds ratio [OR] = 1.144 (1.023-1.278), per $0.1 \%$, per $1.1 \mathrm{mmol} / \mathrm{mol}, p=0.018)$, uric acid (OR $=1.369(1.011-1.853)$, per $1 \mathrm{mg} / \mathrm{dl}, p=0.042)$, and ACI (OR = $1.413(1.132-1.763)$, per 5\%, $p=0.002)$. HbA1c (adjusted OR [aOR] = $1.190(1.032-1.371)$, per $0.1 \%, 1.1 \mathrm{mmol} / \mathrm{mol}, p=0.016)$ and $\mathrm{ACI}(\mathrm{aOR}=1.445(1.110-1.881)$, per $5 \%, p=0.006)$ were revealed as independent risk factors for pre-existing histopathological damages at the baseline biopsy. $\mathrm{HbA} 1 \mathrm{c}$ and $\mathrm{ACI}$ remained as robust independent factors even when other variables were considered. The receiver operating characteristic (ROC) curve analysis showed a cutoff value of $\mathrm{HbA1c}$ at $6.05 \%$ $(42.6 \mathrm{mmol} / \mathrm{mol})$ (area under the curve $[\mathrm{AUC}]=0.615, p=0.057)$ and of $\mathrm{ACI}$ at $2.08 \%$ (AUC $=0.650$, $p=0.013)$, respectively. 
Table 2. Independent predictors associated with pre-existing histopathological damages.

\begin{tabular}{ccccc}
\hline & \multicolumn{2}{c}{ Univariable Analysis } & \multicolumn{2}{c}{ Multivariable Analysis } \\
\hline & OR (95\%CI) & $p$ Value & OR (95\%CI) & $p$ Value \\
\hline Sex (ref. female) & $0.538(0.236-1.229)$ & 0.141 & & \\
Age (years, per 1) & $1.030(0.987-1.076)$ & 0.176 & & \\
Tobacco use & $1.704(0.945-3.073)$ & 0.076 & $1.485(0.769-2.868)$ & 0.239 \\
BP (mmHg, per 1) & $1.013(0.987-1.039)$ & 0.343 & & \\
Hypertension & $1.547(0.668-3.582)$ & 0.309 & & 0.016 \\
HbA1c (\%, per 0.1) & $1.144(1.023-1.278)$ & 0.018 & $1.190(1.032-1.371)$ & 0.663 \\
(mmol/mol, per 1.1) & $1.369(1.011-1.853)$ & 0.042 & $1.087(0.747-1.583)$ & \\
Uric acid (mg/dl, per 1) & $1.001(0.988-1.015)$ & 0.843 & & \\
LDL (mg/dl, per 1) & $1.413(1.132-1.763)$ & 0.002 & $1.445(1.110-1.881)$ & 0.006 \\
ACI (\%, per 5) & $1.050(0.918-1.201)$ & 0.473 & & \\
BMI (kg/m ${ }^{2}$, per 1) & $1.032(0.806-1.323)$ & 0.801 & & \\
PMI (cm $/ \mathrm{m}^{2}$, per 1) & $1.010(0.983-1.037)$ & 0.483 & & \\
eGFR (ml/min/1.73m ${ }^{2}$, per 1) & & & \\
\hline
\end{tabular}

BP: blood pressure. HbA1c: hemoglobin A1c. LDL: low-density lipoprotein. ACI: abdominal calcification index. BMI: body mass index. PMI: 3rd lumber psoas muscle index. eGFR: estimated glomerular filtration. CI: confidence interval.

\subsection{Interaction Analyses}

Figure 2 shows the interaction analyses of aOR for $\mathrm{HbA} 1 \mathrm{c}$ and $\mathrm{ACI}$. There were no interactions between male and female groups (HbA1c, $p=0.640 ; \mathrm{ACI}, p=0.520 ; p$-value for interaction). The impact of $\mathrm{HbA} 1 \mathrm{c}$ and $\mathrm{ACI}$ tended to be observed more in male donors.

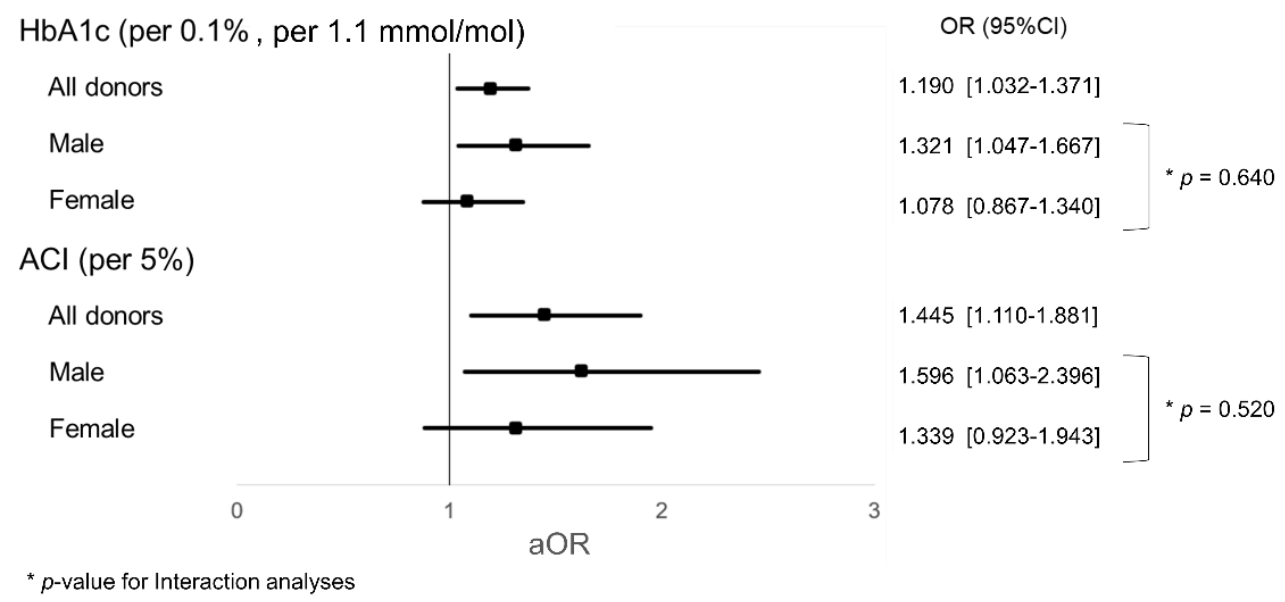

Figure 2. Interaction analyses for $\mathrm{HbA} 1 \mathrm{c}$ and $\mathrm{ACI}$. HbA1c hemoglobin $\mathrm{A} 1 \mathrm{c}$. ACI: abdominal calcification index. aOR: adjusted odds ratio.

\subsection{Distribution of Preoperative Predictors by Pathological Scores}

Figure 3 demonstrates the relationships between preoperative factors and pathological scores. $\mathrm{HbA1c}$ showed a significant correlation with ct scores $(p=0.035 ; p$-values for Kruskal Wallis test). $\mathrm{ACI}$ also showed a positive correlation with ci/ct/ah scores, respectively ( $\mathrm{ACI}$ and ci, $p=0.005 ; \mathrm{ACI}$ and ct, $p=0.021 ; \mathrm{ACI}$ and ah, $p=0.017 ; p$-values for Kruskal Wallis test). 

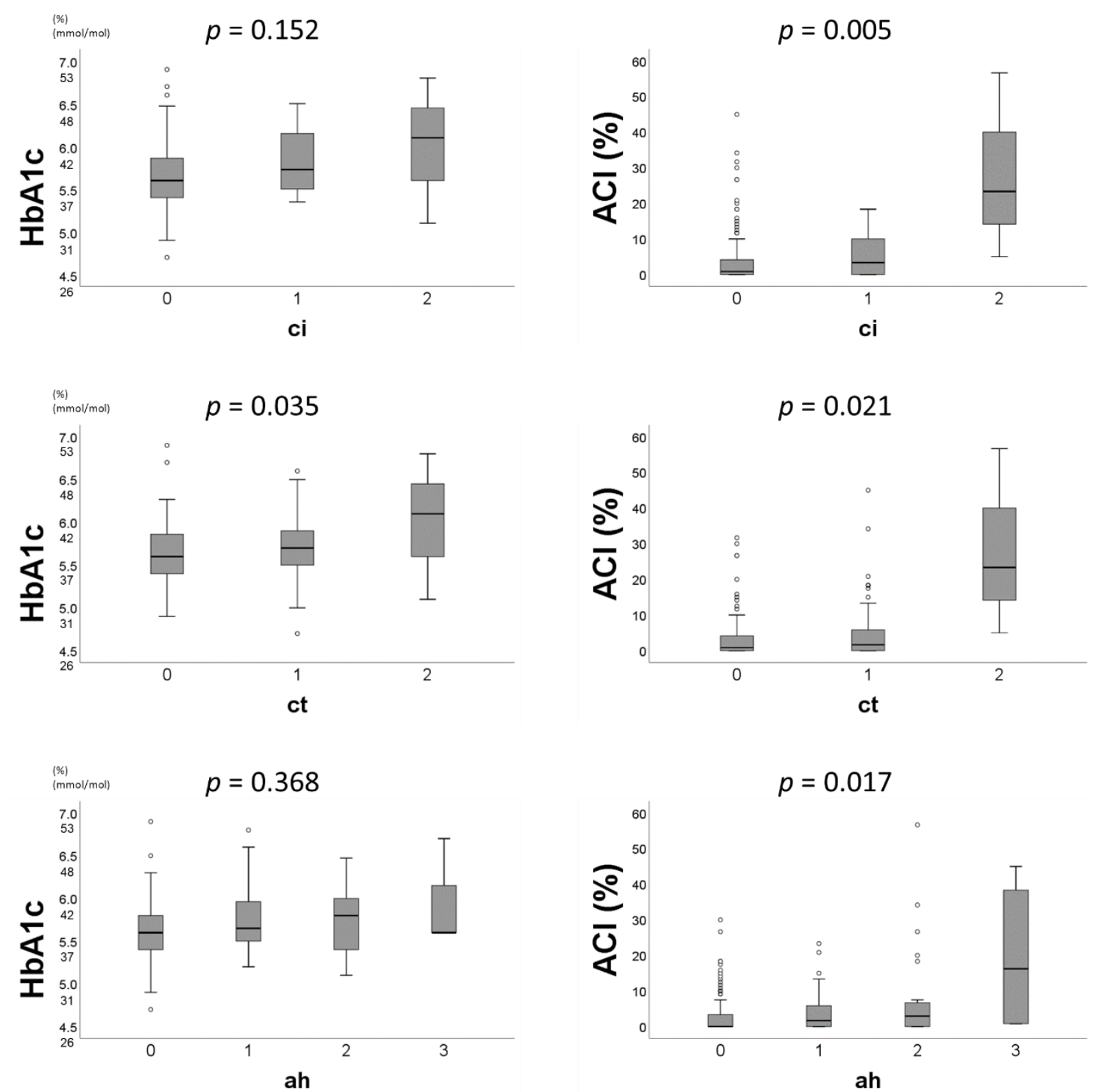

Figure 3. The distribution of $\mathrm{HbA} 1 \mathrm{c}$ and $\mathrm{ACI}$ by ci, ct, and ah score. HbA1c: hemoglobin A1c. ACI: abdominal calcification index. ci: interstitial fibrosis. ct: tubular atrophy. ah: arteriolar hyalinosis.

\section{Discussion}

The present study revealed that $\mathrm{HbA} 1 \mathrm{c}$ and $\mathrm{ACI}$ could be noninvasive preoperative indicators for the prediction of pre-existing histopathological damages in baseline kidney allografts. While $\mathrm{HbA} 1 \mathrm{c}$ did not differ significantly between the two groups, the potential impact of $\mathrm{HbA} 1 \mathrm{c}$ was uncovered after multivariable analyses. We hypothesize that no significant difference was found because the number in the CC group was relatively small and was affected by other factors included in the multivariate analysis.

We have previously shown that pre-existing histopathological damages (ci $+\mathrm{ct} \geqq 1 \cap$ ah $\geqq 1$ ) were correlated with an insufficient one-year recovery of the residual renal function [7]. However, factoring baseline biopsy results into selecting living donors is impractical because it is currently impossible to estimate the "quality" of a donated kidney without biopsies. In the present study, we could elucidate the possible preoperative predictors that reflect the histopathological state of donating kidneys.

The present study indicated that living donors with moderately high $\mathrm{HbA1c}$ may have a positive ct score. Glucose intolerance may become worse after unilateral nephrectomy [34], and microvascular injury and microalbuminuria may be present in prediabetes as an impaired glucose tolerance [35]. A prior study reported that individuals with glucose intolerance and without diabetic complications 
did not develop ESRD after donation [36]. However, they did not review pathological findings at the time of the donation. Considering the pathological perspective, IF/TA and interstitial inflammation were independent variables associated with renal prognosis in diabetes mellitus type 2 patients [37]. Mise et al. also reported that the progression of glomerular tubulointerstitial and vascular lesions were associated with renal death in patients with diabetic nephropathy [38]. These pathological findings have been recognized in the latter stage of developing diabetes mellitus. The present study added the fact that moderately high $\mathrm{HbA} 1 \mathrm{c}$ may be associated with tubular atrophy before the presence of diabetic symptoms. In fact, one of the biggest causes of declination to living donations is the presence of impaired glucose tolerance [39]. Early intervention programs for candidates could increase the number of persons eligible for kidney donations.

Aortic calcification also tended to be associated with pre-existing histopathological damages of allografts in the present study. Consistent with our findings, a previous study reported that living donors with aortic calcification had a higher than average probability of delayed renal function recovery after donation [40]. Aortic stiffness of living donors may also contribute to the recipient outcome beyond other parameters [41]. Another report also demonstrated that allografts from donors with vascular calcification had a high percentage of vascular fibrous intimal thickening and arteriolar hyaline thickening in the six-month surveillance biopsy [42]. The present study revealed that a higher ACI was associated with higher $\mathrm{ci}, \mathrm{ct}$, and ah scores. The present study was in line with prior studies and added that even a low ACI may be associated with arteriolar hyalinosis as well as IF/TA in the baseline allografts. While ACI is not a perfect alternative for arteriosclerosis and aortic stiffness, ACI may be one of many noninvasive markers to identify the degree of arteriolar hyalinosis in donated kidneys.

The degree of sarcopenia did not show a correlation with pre-existing histopathological damages in the present study. Sarcopenia was highly prevalent in elderly patients with ESRD (approximately 30\%) [43]. Although there are many studies regarding the impact of sarcopenia on graft outcomes [44-47], the relationship between a donor's sarcopenia and renal function is little known. Further studies are needed to investigate the relationship between preoperative sarcopenia and renal function.

There are gender differences in the occurrence of hypertensive kidney disease. Though we could not prove the relationship between female preoperative biomarkers and subclinical kidney dysfunction, the ah score was significantly associated with a history of hypertension, especially in women. Female kidneys were more vulnerable to hypertension [48], and the rate of renal disease progression was faster in women with hypertension than in men with hypertension [49]. The Italy Developing Education and Awareness on Microalbuminuria in Patients with Hypertensive Disease study reported that women had lower GFR than men despite comparable blood pressures [50]. Consistent with former studies, the present study reinforced that female kidneys were vulnerable to a hypertensive state.

Subclinical kidney damages were not proven to be associated with the donor age in the present study. In Japan, living donors were seen to be getting older as there are many kidney transplantations from spouses and parents due to the shortage of organs [1]. The decreasing rate of kidney function after donation in elderly donors was almost equal to young donors [51,52]. Therefore, donation from elderly people tends to be acceptable. However, the present study suggested that subclinical statuses such as $\mathrm{HbA} 1 \mathrm{c}$ and ACI reflected "biological" aging in living kidney donors. We need to start a larger study on the relationship between preoperative factors and biopsy findings, especially among elderly donors.

\section{Limitations}

Some limitations of the study should be acknowledged. First, this was a single-center cross-sectional study, and the sample size was relatively small; there were only 27 donors in the CC group. Second, the possibility of intraoperative influences was not considered when interpreting 1-h biopsies. Some troubles during surgery, such as bleeding from the anastomosis and acute tubular necrosis after reperfusion, may affect the kidney biopsy result [26]. These influences should have been 
accounted for. Third, a type of selection bias may exist in this study. All donors may hope to help their families or their spouses by donation. Therefore, participants may be particularly careful of their own health so as to be eligible to be donors. Fourth, the population of the present study was homogenous and made up of a single ethnicity. It would be hard to adapt Japanese data to other ethnicities.

While $\mathrm{HbA} 1 \mathrm{c}$ and $\mathrm{ACI}$ tended to be associated with pre-existing histopathological damages as mentioned above, their impact may be relatively limited. There are two reasons. First, the ROC curve analysis showed a relatively low AUC (HbA1c, 0.615; ACI, 0.650). This indicated that the accuracy of the cutoff values may be not very reliable. Second, in Figure 3, the correlation between $\mathrm{HbA1c}$ and the chronicity subscores of the Banff classification was proven only in relation to the ct scores, while the correlation between ACI and the chronicity subscores could be shown. On the basis of histopathological findings of diabetic nephropathy [37], these results may have been contributed to by the small sample size of donors. The present study could state that $\mathrm{HbA} 1 \mathrm{c}$ and $\mathrm{ACI}$ were independent risk factors for predicting pre-existing histopathological damages; however, further research may be needed to reveal more reliable results regarding $\mathrm{HbA} 1 \mathrm{c}$ and ACI.

\section{Conclusions}

This study suggested that $\mathrm{HbA1c}$ and $\mathrm{ACI}$ might be independent risk factors of pre-existing histopathological damages in the allograft. These noninvasive markers should be factored into the living donor selection process as well as into the careful follow-up of living donors.

Author Contributions: K.T. and S.Y. designed the study, wrote the initial draft of the manuscript, analyzed all data. S.Y., Y.H. and K.O. assisted in the preparation of the manuscript and provided advice about data collection and interpretation. M.T. wrote down and managed preoperative data. A.T. made pathological judgments of all biopsies. All other authors critically reviewed the manuscript. All authors have read and agreed to the published version of the manuscript.

Funding: This research received no external funding.

Conflicts of Interest: The authors declare no conflict of interest.

\section{Abbreviations}

$\begin{array}{ll}\text { ACI } & \text { Aortic calcification index } \\ \text { ah } & \text { Arteriolar hyalinosis } \\ \text { AUC } & \text { Area under the curve } \\ \text { CC } & \text { Chronic change } \\ \text { ci } & \text { Interstitial fibrosis } \\ \text { ct } & \text { Tubular atrophy } \\ \text { CT } & \text { Computed tomography } \\ \text { eGFR } & \text { estimated glomerular filtration rate } \\ \text { ESRD } & \text { End-stage renal disease } \\ \text { GFR } & \text { Glomerular filtration rate } \\ \text { HbA1c } & \text { Hemoglobin A1c } \\ \text { HU } & \text { Hounsfield unit } \\ \text { IFCC } & \text { International Federation of Clinical Chemistry and Laboratory Medicine } \\ \text { IF/TA } & \text { Interstitial fibrosis/tubular atrophy } \\ \text { JDS } & \text { Japan Diabetes Society } \\ \text { LDL } & \text { Low-density lipoprotein } \\ \text { NGSP } & \text { National Glycohemoglobin Standardization Program } \\ \text { OR } & \text { Odds ratio } \\ \text { PMI } & \text { Psoas muscle index } \\ \text { ROC } & \text { Receiver operating characteristic }\end{array}$




\section{References}

1. Japanese Society for Clinical Renal Transplantation; The Japan Society for Transplantation. Annual Progress Report from the Japanese Renal Transplant Registry: Number of Renal Transplantations in 2018 and Follow-up Survey. Jpn. J. Transplant. 2019, 54, 61-80. [CrossRef]

2. Mjoen, G.; Hallan, S.; Hartmann, A.; Foss, A.; Midtvedt, K.; Oyen, O.; Reisaeter, A.; Pfeffer, P.; Jenssen, T.; Leivestad, T.; et al. Long-term risks for kidney donors. Kidney Int. 2014, 86, 162-167. [CrossRef] [PubMed]

3. Muzaale, A.D.; Massie, A.B.; Wang, M.C.; Montgomery, R.A.; McBride, M.A.; Wainright, J.L.; Segev, D.L. Risk of end-stage renal disease following live kidney donation. JAMA 2014, 311, 579-586. [CrossRef] [PubMed]

4. $\quad$ Berger, J.C.; Muzaale, A.D.; James, N.; Hoque, M.; Wang, J.M.; Montgomery, R.A.; Massie, A.B.; Hall, E.C.; Segev, D.L. Living kidney donors ages 70 and older: Recipient and donor outcomes. Clin. J. Am. Soc. Nephrol. 2011, 6, 2887-2893. [CrossRef] [PubMed]

5. Delmonico, F. A Report of the Amsterdam Forum On the Care of the Live Kidney Donor: Data and Medical Guidelines. Transplantation 2005, 79, S53-S66.

6. Noppakun, K.; Cosio, F.G.; Dean, P.G.; Taler, S.J.; Wauters, R.; Grande, J.P. Living donor age and kidney transplant outcomes. Am. J. Transpl. 2011, 11, 1279-1286. [CrossRef]

7. Nishida, S.; Hidaka, Y.; Toyoda, M.; Kinoshita, K.; Tanaka, K.; Kawabata, C.; Hamanoue, S.; Inadome, A.; Yokomizo, H.; Takeda, A.; et al. Factors related to suboptimal recovery of renal function after living donor nephrectomy: A retrospective study. BMC Nephrol. 2019, 20, 403. [CrossRef]

8. Roufosse, C.; Simmonds, N.; Clahsen-van Groningen, M.; Haas, M.; Henriksen, K.J.; Horsfield, C.; Loupy, A.; Mengel, M.; Perkowska-Ptasinska, A.; Rabant, M.; et al. A 2018 Reference Guide to the Banff Classification of Renal Allograft Pathology. Transplantation 2018, 102, 1795-1814. [CrossRef]

9. Hommos, M.S.; Rule, A.D. Should We Always Defer Treatment of Kidney Disease When There Is Extensive Interstitial Fibrosis on Biopsy? Am. J. Nephrol. 2016, 44, 286-288. [CrossRef] [PubMed]

10. Nangaku, M. Chronic hypoxia and tubulointerstitial injury: A final common pathway to end-stage renal failure. J. Am. Soc. Nephrol. 2006, 17, 17-25. [CrossRef]

11. Fioretto, P.; Steffes, M.W.; Sutherland, D.E.; Mauer, M. Sequential renal biopsies in insulin-dependent diabetic patients: Structural factors associated with clinical progression. Kidney Int. 1995, 48, 1929-1935. [CrossRef] [PubMed]

12. Zamami, R.; Kohagura, K.; Miyagi, T.; Kinjyo, T.; Shiota, K.; Ohya, Y. Modification of the impact of hypertension on proteinuria by renal arteriolar hyalinosis in nonnephrotic chronic kidney disease. J. Hypertens. 2016, 34, 2274-2279. [CrossRef]

13. Tozawa, M.; Iseki, K.; Iseki, C.; Kinjo, K.; Ikemiya, Y.; Takishita, S. Blood pressure predicts risk of developing end-stage renal disease in men and women. Hypertension 2003, 41, 1341-1345. [CrossRef] [PubMed]

14. Vupputuri, S.; Batuman, V.; Muntner, P.; Bazzano, L.A.; Lefante, J.J.; Whelton, P.K.; He, J. Effect of blood pressure on early decline in kidney function among hypertensive men. Hypertension 2003, 42, 1144-1149. [CrossRef] [PubMed]

15. Yamagata, K.; Ishida, K.; Sairenchi, T.; Takahashi, H.; Ohba, S.; Shiigai, T.; Narita, M.; Koyama, A. Risk factors for chronic kidney disease in a community-based population: A 10-year follow-up study. Kidney Int. 2007, 71, 159-166. [CrossRef]

16. Adler, A.I.; Stevens, R.J.; Manley, S.E.; Bilous, R.W.; Cull, C.A.; Holman, R.R. Development and progression of nephropathy in type 2 diabetes: The United Kingdom Prospective Diabetes Study (UKPDS 64). Kidney Int. 2003, 63, 225-232. [CrossRef]

17. Echouffo-Tcheugui, J.B.; Narayan, K.M.; Weisman, D.; Golden, S.H.; Jaar, B.G. Association between prediabetes and risk of chronic kidney disease: A systematic review and meta-analysis. Diabet Med. 2016, 33, 1615-1624. [CrossRef]

18. Mänttäri, M.; Tiula, E.; Alikoski, T.; Manninen, V. Effects of hypertension and dyslipidemia on the decline in renal function. Hypertension 1995, 26, 670-675. [CrossRef]

19. Schaeffner, E.S.; Kurth, T.; Curhan, G.C.; Glynn, R.J.; Rexrode, K.M.; Baigent, C.; Buring, J.E.; Gaziano, J.M. Cholesterol and the risk of renal dysfunction in apparently healthy men. J. Am. Soc. Nephrol. 2003, 14, 2084-2091. 
20. Peeters, M.J.; van den Brand, J.A.; van Zuilen, A.D.; Koster, Y.; Bots, M.L.; Vervloet, M.G.; Blankestijn, P.J.; Wetzels, J.F. Abdominal aortic calcification in patients with CKD. J. Nephrol. 2017, 30, 109-118. [CrossRef]

21. Souza, V.A.; Oliveira, D.; Barbosa, S.R.; Correa, J.; Colugnati, F.A.B.; Mansur, H.N.; Fernandes, N.; Bastos, M.G. Sarcopenia in patients with chronic kidney disease not yet on dialysis: Analysis of the prevalence and associated factors. PLoS ONE 2017, 12, e0176230. [CrossRef] [PubMed]

22. Tomaszewski, M.; Charchar, F.J.; Maric, C.; McClure, J.; Crawford, L.; Grzeszczak, W.; Sattar, N.; Zukowska-Szczechowska, E.; Dominiczak, A.F. Glomerular hyperfiltration: A new marker of metabolic risk. Kidney Int. 2007, 71, 816-821. [CrossRef] [PubMed]

23. Helal, I.; Fick-Brosnahan, G.M.; Reed-Gitomer, B.; Schrier, R.W. Glomerular hyperfiltration: Definitions, mechanisms and clinical implications. Nat. Rev. Nephrol. 2012, 8, 293-300. [CrossRef] [PubMed]

24. Srivastava, T.; Hariharan, S.; Alon, U.S.; McCarthy, E.T.; Sharma, R.; El-Meanawy, A.; Savin, V.J.; Sharma, M. Hyperfiltration-mediated Injury in the Remaining Kidney of a Transplant Donor. Transplantation 2018, 102, 1624-1635. [CrossRef]

25. Morozumi, K. Clinical practice guidelines for renal transplant donors and recipients in Japan. Jpn. J. Transplant. 2014, 49, 410-416. [CrossRef]

26. Sakai, K.; Oguchi, H.; Muramatsu, M.; Shishido, S. Protocol graft biopsy in kidney transplantation. Nephrol. (Carlton) 2018, 23 (Suppl. S2), 38-44. [CrossRef]

27. Kashiwagi, A.; Kasuga, M.; Araki, E.; Oka, Y.; Hanafusa, T.; Ito, H.; Tominaga, M.; Oikawa, S.; Noda, M.; Kawamura, T.; et al. International clinical harmonization of glycated hemoglobin in Japan: From Japan Diabetes Society to National Glycohemoglobin Standardization Program values. J. Diabetes Investig. 2012, 3, 39-40. [CrossRef]

28. Sacks, D.B. Measurement of hemoglobin A(1c): A new twist on the path to harmony. Diabetes Care 2012, 35, 2674-2680. [CrossRef]

29. Matsuo, S.; Imai, E.; Horio, M.; Yasuda, Y.; Tomita, K.; Nitta, K.; Yamagata, K.; Tomino, Y.; Yokoyama, H.; Hishida, A. Revised equations for estimated GFR from serum creatinine in Japan. Am. J. Kidney Dis. 2009, 53, 982-992. [CrossRef]

30. Taniwaki, H.; Ishimura, E.; Tabata, T.; Tsujimoto, Y.; Shioi, A.; Shoji, T.; Inaba, M.; Inoue, T.; Nishizawa, Y. Aortic calcification in haemodialysis patients with diabetes mellitus. Nephrol. Dial. Transpl. 2005, 20, 2472-2478. [CrossRef]

31. Furusawa, K.; Takeshita, K.; Suzuki, S.; Tatami, Y.; Morimoto, R.; Okumura, T.; Yasuda, Y.; Murohara, T. Assessment of abdominal aortic calcification by computed tomography for prediction of latent left ventricular stiffness and future cardiovascular risk in pre-dialysis patients with chronic kidney disease: A single center cross-sectional study. Int. J. Med. Sci. 2019, 16, 939-948. [CrossRef] [PubMed]

32. Hamaguchi, Y.; Kaido, T.; Okumura, S.; Kobayashi, A.; Hammad, A.; Tamai, Y.; Inagaki, N.; Uemoto, S. Proposal for new diagnostic criteria for low skeletal muscle mass based on computed tomography imaging in Asian adults. Nutrition 2016, 32, 1200-1205. [CrossRef] [PubMed]

33. Vandenbroucke, J.P.; von Elm, E.; Altman, D.G.; Gotzsche, P.C.; Mulrow, C.D.; Pocock, S.J.; Poole, C.; Schlesselman, J.J.; Egger, M.; Initiative, S. Strengthening the Reporting of Observational Studies in Epidemiology (STROBE): Explanation and elaboration. Int. J. Surg. 2014, 12, 1500-1524. [CrossRef] [PubMed]

34. Shehab-Eldin, W.; Shoeb, S.; Khamis, S.; Salah, Y.; Shoker, A. Susceptibility to insulin resistance after kidney donation: A pilot observational study. Am. J. Nephrol. 2009, 30, 371-376. [CrossRef]

35. Singleton, J.R.; Smith, A.G.; Russell, J.W.; Feldman, E.L. Microvascular complications of impaired glucose tolerance. Diabetes 2003, 52, 2867-2873. [CrossRef]

36. Okamoto, M.; Suzuki, T.; Fujiki, M.; Nobori, S.; Ushigome, H.; Sakamoto, S.; Yoshimura, N. The consequences for live kidney donors with preexisting glucose intolerance without diabetic complication: Analysis at a single Japanese center. Transplantation 2010, 89, 1391-1395. [CrossRef]

37. Okada, T.; Nagao, T.; Matsumoto, H.; Nagaoka, Y.; Wada, T.; Nakao, T. Histological predictors for renal prognosis in diabetic nephropathy in diabetes mellitus type 2 patients with overt proteinuria. Nephrol. (Carlton) 2012, 17, 68-75. [CrossRef]

38. Mise, K.; Hoshino, J.; Ubara, Y.; Sumida, K.; Hiramatsu, R.; Hasegawa, E.; Yamanouchi, M.; Hayami, N.; Suwabe, T.; Sawa, N.; et al. Renal prognosis a long time after renal biopsy on patients with diabetic nephropathy. Nephrol. Dial. Transpl. 2014, 29, 109-118. [CrossRef] 
39. Guthoff, M.; Nadalin, S.; Fritsche, A.; Königsrainer, A.; Häring, H.U.; Heyne, N. The Medically Complex Living Kidney Donor: Glucose Metabolism as Principal Cause of Donor Declination. Ann. Transpl. 2016, 21, 39-45. [CrossRef]

40. Yoon, Y.E.; Han, W.K.; Lee, H.H.; Chang, M.Y.; Huh, K.H.; Jung, D.C.; Kim, Y.S.; Oh, Y.T. Abdominal Aortic Calcification in Living Kidney Donors. Transpl. Proc. 2016, 48, 720-724. [CrossRef]

41. Bahous, S.A.; Stephan, A.; Blacher, J.; Safar, M. Cardiovascular and renal outcome in recipients of kidney grafts from living donors: Role of aortic stiffness. Nephrol. Dial. Transpl. 2012, 27, 2095-2100. [CrossRef] [PubMed]

42. Wu, E.H.; Wojciechowski, D.; Chandran, S.; Yeh, B.M.; Park, M.; Westphalen, A.; Wang, Z.J. Prevalence of abdominal aortic calcifications in older living renal donors and its effect on graft function and histology. Transpl. Int. 2015, 28, 1172-1178. [CrossRef] [PubMed]

43. Kim, J.K.; Choi, S.R.; Choi, M.J.; Kim, S.G.; Lee, Y.K.; Noh, J.W.; Kim, H.J.; Song, Y.R. Prevalence of and factors associated with sarcopenia in elderly patients with end-stage renal disease. Clin. Nutr. 2014, 33, 64-68. [CrossRef] [PubMed]

44. Garonzik-Wang, J.M.; Govindan, P.; Grinnan, J.W.; Liu, M.; Ali, H.M.; Chakraborty, A.; Jain, V.; Ros, R.L.; James, N.T.; Kucirka, L.M.; et al. Frailty and delayed graft function in kidney transplant recipients. Arch. Surg. 2012, 147, 190-193. [CrossRef]

45. McAdams-DeMarco, M.A.; Law, A.; King, E.; Orandi, B.; Salter, M.; Gupta, N.; Chow, E.; Alachkar, N.; Desai, N.; Varadhan, R.; et al. Frailty and mortality in kidney transplant recipients. Am. J. Transpl. 2015, 15, 149-154. [CrossRef]

46. McAdams-DeMarco, M.A.; Law, A.; Salter, M.L.; Chow, E.; Grams, M.; Walston, J.; Segev, D.L. Frailty and early hospital readmission after kidney transplantation. Am. J. Transpl. 2013, 13, 2091-2095. [CrossRef]

47. Streja, E.; Molnar, M.Z.; Kovesdy, C.P.; Bunnapradist, S.; Jing, J.; Nissenson, A.R.; Mucsi, I.; Danovitch, G.M.; Kalantar-Zadeh, K. Associations of pretransplant weight and muscle mass with mortality in renal transplant recipients. Clin. J. Am. Soc. Nephrol. 2011, 6, 1463-1473. [CrossRef]

48. Tziomalos, K.; Giampatzis, V.; Baltatzi, M.; Efthymiou, E.; Psianou, K.; Papastergiou, N.; Magkou, D.; Bougatsa, V.; Savopoulos, C.; Hatzitolios, A.I. Sex-specific differences in cardiovascular risk factors and blood pressure control in hypertensive patients. J. Clin. Hypertens. (Greenwich) 2014, 16, 309-312. [CrossRef]

49. Sullivan, J.C.; Gillis, E.E. Sex and gender differences in hypertensive kidney injury. Am. J. Physiol. Ren. Physiol. 2017, 313, F1009-F1017. [CrossRef]

50. Muiesan, M.L.; Ambrosioni, E.; Costa, F.V.; Leonetti, G.; Pessina, A.C.; Salvetti, M.; Trimarco, B.; Volpe, M.; Pontremoli, R.; Deferrari, G.; et al. Sex differences in hypertension-related renal and cardiovascular diseases in Italy: The I-DEMAND study. J. Hypertens. 2012, 30, 2378-2386. [CrossRef]

51. Dols, L.F.; Kok, N.F.; Roodnat, J.I.; Tran, T.C.; Terkivatan, T.; Zuidema, W.C.; Weimar, W.; Ijzermans, J.N. Living kidney donors: Impact of age on long-term safety. Am. J. Transpl. 2011, 11, 737-742. [CrossRef] [PubMed]

52. Toyoda, M.; Yamanaga, S.; Kawabata, C.; Hidaka, Y.; Inadome, A.; Arakane, F.; Uekihara, S.; Seishi, I. Long-term safety of living kidney donors aged 60 and older. Transpl. Proc. 2014, 46, 318-320. [CrossRef] [PubMed]

(C) 2020 by the authors. Licensee MDPI, Basel, Switzerland. This article is an open access article distributed under the terms and conditions of the Creative Commons Attribution (CC BY) license (http://creativecommons.org/licenses/by/4.0/). 